\title{
Enhancement of Trichoderma Harzianum Activity Against Sclerotinia sclerotiorum by Overexpression of Chit42
}

\author{
Mojegan Kowsari ${ }^{1,2} ;$ Mohammad Reza Zamani $^{1, *} ;$ Mostafa Motallebi $^{1}$ \\ ${ }^{1}$ National Institute of Genetic Engineering and Biotechnology, Tehran, I.R. IRAN \\ ${ }^{2}$ Agricultural Biotechnology Research Institute of Iran, Karaj, I.R. IRAN \\ *Corresponding author: Mohammad Reza Zamani, National Institute of Genetic Engineering and Biotechnology, Shahrak-e Pajoohesh, Tehran-Karaj Highway, P.O. Box: 14965161, \\ Tehran, I.R. IRAN. Tel: +98-2144580363, Fax:+98-2144580363, E-mail: zamani@nigeb.ac.ir
}

Received: July 27, 2013; Revised: November 5, 2013; Accepted: January 27, 2014

Backgoround:Plant diseases, caused by a wide range of phytopathogenic fungi, could be managed using of Trichoderma sp, as a biocontrol agent. Cell wall degrading enzymes like chitinase from T. harzianum are important means for fungal pathogen inhibition. Overexpression of these chitinase enzymes can improve the antagonistic potential of Trichoderma sp. strains.

Objectives: This study aimed to produce a new enhanced biocontrol system of Trichoderma harzianum, overexpressing chit42 gene. The improved T. harzianum could be an appropriate biocontrol agent for controlling the stem rot disease of canola caused by Sclerotinia sclerotiorum.

Materials and Methods: T. harzianum protoplast cotransformation was carried out by pLMRS3-Chit42 and p3SR2 plasmids. The transformants were selected based on their growth on colloidal chitin containing medium. The improvement of transformants was investigated by quantification of mRNA using real-time quantitative polymerase chain reaction (RT-PCR) and measurement of chitinase activity in the medium containing colloidal chitin as the carbon source. Furthermore, the antagonistic activity of transformants against S. sclerotiorum was assessed by dual culture experiments.

Results: The overexpressing transformants of Chit42 displayed higher levels of chitinase activity to inhibit $S$. sclerotiorum growth compared with the wild type. The results indicated that the value of the chitinase activity $\left(126.42+0.07 \mathrm{U}_{\mathrm{ml}}{ }^{-1}\right)$ of Chit $42-9$ increased 64.17 fold. Transcriptomic analysis demonstrated that Chit $42-9$ transformant expressed 5.2 fold of chit 42 transcript as compared with the parent strain. Biocontrol inhibition of this transformant was 4.98-fold more compared with the non-transformant type.

Conclusions: The improved Chit42-9 transformant can be used for biocontrolling S. sclerotiorum, cause of stem rot disease in canola.

Keywords: Chitinase; Real-Time Polymerase Chain Reaction; Sclerotinia sclerotiorum; Trichoderma

\section{Background}

The genus Trichoderma, a soil borne group of fungi, acts as important biocontrol agents against phytopathogenic fungi. More than 50 bioproducts of Trichoderma have been registered and available on the market (1). Trichoderma strains are ubiquitous biocontrol agents because of their high reproductive capacity, strong aggressiveness against pathogens, ability to survive under difficult conditions, efficiency in promoting plant growth and defense mechanisms (2).

Parasitism, competition and antibiosis are the main mechanisms of biocontrol in Trichoderma sp (3). Parasitism is a common cause for pathogen death (4). Hydrolytic enzymes are important factors during parasitism for cell wall degradation of pathogens. Trichoderma sp. are efficient sources for the production of destructive enzymes like chitinases (5).
These enzymes, including chitinases are capable of reducing or stopping spore germination and hyphal growth of fungal pathogens (6). Among chitinases, chitinase 42 plays a major role in the inhibition of pathogen growth (7). The expression of chit42 gene is strongly induced during fungus-fungus interaction and when the colloidal chitin is the sole carbon source in growth media $(8,9)$.

The biocontrol activities of Trichoderma sp. can be enhanced through overexpressing the chitinolytic enzymes by genetic engineering (10-12). Overexpression of single chitinase can improve the mycoparasitic potential of the biocontrol agent (13-15). The improved Trichoderma sp could reduce the development of S. sclerotiorum, the causal agent of stem rot disease in canola plants.

Sclerotinia stem rot is a destructive disease which in serious epidemic years may reduce the canola yield by $20-25 \%(16)$.

Implication for health policy/practice/research/medical education:

Production of a new enhanced biocontrol system of Trichoderma harzianum, by overexpressing chit42 gene could benefit crop yield production of canola. Copyright @ 2014, National Institute of Genetic Engineering and Biotechnology; Published by Kowsar Corp. This is an open-access article distributed under the terms of the Creative Commons Attribution License, which permits unrestricted use, distribution, and reproduction in any medium, provided the original work is properly cited. 
Kowsari Met al.

\section{Objectives}

The objectives of this study was to improve the antagonistic effect of the biocontrol agent $T$. harzianum by overexpressing the chit42 gene, derived from T. atroviride under the control of a constitutive promoter. The improved strain may be useful to control the stem rot disease of canola.

\section{Materials and Methods}

All chemicals were purchased from Merck (Germany), unless otherwise stated.

\subsection{Microorganisms and Plasmids}

Trichoderma harzianum and Sclerotinia sclerotiorum were provided by the Agricultural Biotechnology Research Institute of Iran, type collection culture. Plasmid p3SR2, which carries the amdS gene (coding for acetamidase as a selectable marker) from Aspergillus nidulans was used. The pLMRS3 plasmid, which carried the constitutive promoter pki1 from $T$. reesei and the cbh2 terminator from $T$. reesei, cellobiohydrolaseII was used as the expression vector.

\subsection{Growth Media and Culture Condition}

T. harzianum and S. sclerotiorum were maintained on PDA (potato dextrose agar) slants. The colloidal chitin agar (CCA) selective medium was composed of following compounds: colloidal chitin 5.0 g.l ${ }^{-1}$; sucrose 1.0 g.l ${ }^{-1} ; \mathrm{NaNO}_{3}$ 2.0 g.l ${ }^{-1} ; \mathrm{K}^{2} \mathrm{HPO}_{4} 1.0$ g.l ${ }^{-1}$; $\mathrm{KCl}^{0} .5$ g.l $^{-1} ; \mathrm{MgSO}_{4} 0.5$ g.l ${ }^{-1}$; $\mathrm{FeSO}_{4} 0.01 \mathrm{~g} . \mathrm{l}^{-1}$; agar $15 \mathrm{~g} . \mathrm{l}^{-1}$; and distilled water $1000 \mathrm{ml}$ at $\mathrm{pH}$ 6.5. Trichoderma minimal media (MM) contained the following chemicals (in mg/mL): $\left(\mathrm{NH}_{4}\right) 2 \mathrm{SO} 4,5 ; \mathrm{KH}_{2} \mathrm{PO}_{4}$, $15 ; \mathrm{MgSO}_{4}, 0.6 ; \mathrm{CaCl}_{2}, 0.6 ; \mathrm{CoCl}_{2}, 0.002 ; \mathrm{FeSO}_{4} .7 \mathrm{H}_{2} \mathrm{O}, 0.005$; $\mathrm{MnSO}_{4} . \mathrm{H}_{2} \mathrm{O}, 0.0016$; and $\mathrm{ZnSO}_{4} .7 \mathrm{H}_{2} \mathrm{O}, 0.0014$.

The selective medium for amdS expression was MM containing $10 \mathrm{mM}$ acetamide as the sole nitrogen source and 12.5 mM CsCl (MMA). The E. coli DH5 $\alpha$ was grown in a Luria-Bertani (LB) medium at $37^{\circ} \mathrm{C}$; the media were supplemented with ampicillin (SIGMA, 100 g.ml -1). DNA modifying enzymes were obtained from Fermentase and Roche Biochemical.

\subsection{Construction of Expression Cassette}

The RNA from powdered mycelia was isolated using RNeasy Plant Mini Kit (Qiagen, Germany) according to the manufacturer's recommendations. Molecular biology procedures were performed following the standard protocols $(17,18)$. The 1278 bp chit42 cDNA from T. atroviride (DQ022674) was amplified using primers Pf1 (5'GCTCTAGAATGTTGGGCTTCCTCGGAAAG3') and Prx (5'GCTCTA GACTAGTTGAGACCGCTTCGGAT3'), which were designed along with the XbaI recognition sites, by Pfu DNA polymerase. The PCR mixture contained the standard concentrations of DNA, dNTPs, primers, and DNA polymerases.
The PCR program consisted of 35 repetitive cycles at $94^{\circ} \mathrm{C}$ for one minute, $62^{\circ} \mathrm{C}$ for one minute and $72^{\circ} \mathrm{C}$ for one minute and a separate step for 10 minutes at $72^{\circ} \mathrm{C}$. Amplified fragment was purified using a PCR product purification kit (Roche). The blunt-ended fragment was ligated to vector pJET (pJEchit42) and sequenced. The XbaI digested fragment was subcloned into the XbaI site of the pLMRS3 expression vector to create pLMRS3-chit42, which was used for protoplast transformation.

\subsection{Cotransformation}

Protoplast preparation and transformation were carried out according to the method of Penttila et al. (19). T. harzianum wild type was cotransformed with chitinasecontaining plasmid pLMRS3-chit42 and p3SR2 plasmid. Plasmid p3SR2 carries the amdS gene from Aspergillus nidulans, which codes for acetamidase as the selectable marker.

Cotransformation was conducted with a 1:10 (p3SR2/ pLMRS3-chit42 plasmid ratio, and 200-1000 $\mu \mathrm{L}$ aliquots of the transformed protoplasts were plated in $0.75 \%(\mathrm{w} / \mathrm{v}) \mathrm{se}$ lective top agar containing one $\mathrm{M}$ sorbitol as the osmotic stabilizer.

The selective medium for amdS expression was MM glucose containing $10 \mathrm{mM}$ acetamide as the sole nitrogen source instead of $\left(\mathrm{NH}_{4}\right)_{2} \mathrm{SO}_{4}$ and $12.5 \mathrm{mM} \mathrm{CsCl}$. Individual colonies were randomly chosen for amdS in the selective medium and incubated at $28^{\circ} \mathrm{C}$ for 5 days. Protoplasts were placed on a $2 \%(\mathrm{w} / \mathrm{v})$ CCA selective medium. The regeneration of protoplast and the colony developments were observed on the plates that were incubated at room temperature.

Regenerated transformants were selected based on their growth rate on the selective medium. One mycelial disk ( $5 \mathrm{mM}$ ) of each transformant was inoculated on $0.5 \%$ (w/v) CCA and PDA media and incubated at $28^{\circ} \mathrm{C}$ for four days.

\subsection{Transcriptomic Analysis by Quantitative Real- Time RT-PCR}

Expression levels of chit42 were quantified by real-time RT-PCR assay. Total RNA was isolated from $100 \mathrm{mg}$ of freeze-dried mycelia powder of single spore of selected transformants and wild type using the RNeasy Plant Mini Kit(Qiagen). The cDNA were synthesized from $1 \mu \mathrm{g}$ of total RNA using a cDNA synthesis kit with an oligo (dT) primer. One microgram of the cDNA was used in the PCR reaction (with chiF/chiR and $\beta$ tubuF/ $\beta$ tubuR as specific primers).

Real-time PCR was performed using an ABI system with a SYBR green master mix. All PCRs were performed in triplicate, and in a total volume of $10 \mu$ for 40 cycles under the following conditions: denaturation, $95^{\circ} \mathrm{C}, 45$ seconds; annealing, $60^{\circ} \mathrm{C}$, one minute; and extension, $72^{\circ} \mathrm{C}$, one minute.

The number of cDNA transcripts was normalized 
against the expression of the housekeeping $\beta$-tubulin gene (20). The expression level was calculated by the formula 2 - $\Delta \Delta \mathrm{CT}(21)$.

\subsection{Chitinase Activity}

Chitinase activity was assayed according to the Boller and Mauch method (22). N-Acetyl-D-glucosamine (NAG) standard curve was prepared according to the procedures set out by Reissig and associates (23). Colloidal chitin was prepared from crab shell chitin (24). Mycelium was prepared by inoculating the spores into PDB (potato dextrose broth) medium and incubated on a rotary shaker at $28^{\circ} \mathrm{C}$ for three days under aerobic conditions.

The mycelium (1.0 g) was transferred into $100 \mathrm{ml}$ fermentation medium $\left(\mathrm{MgSO}_{4} .7 \mathrm{H}_{2} \mathrm{O}, 0.6\right.$ g. $\mathrm{l}^{-1} ; \mathrm{FeSO}_{4} .7 \mathrm{H}_{2} \mathrm{O}$, 0.1 g.l ${ }^{-1} ; \mathrm{NH}_{4} \mathrm{NO}_{3}, 3.0$ g.l ${ }^{-1} ; \mathrm{KH}_{2} \mathrm{PO}_{4}, 2.0$ g.l ${ }^{-1}$; and colloidal chitin $20 \% \mathrm{w} / \mathrm{v}$ ) using $10 \mathrm{~g} . \mathrm{l}^{-1}$ colloidal chitin as the sole carbon source.

The supernatant was obtained by removing the mycelium from filtrate after 48 hours. Each experiment was performed in triplicates, and the mean value was taken. Standard deviation was calculated using functions of MS Excel application (Microsoft Corporation). The released $\mathrm{N}$-acetylglucosamine (GlcNAc) was measured according to the procedures set out by Reissig et al. (23). A unit was defined as the amount of the enzyme that releases $1 \mu \mathrm{mol}$ GlcNAc per 60 minutes.

\subsection{Test for Antagonism}

Antagonistic activity of Trichoderma wild-type and its transformants against $S$. sclerotiorum were assessed using the dual culture technique (10). One mycelial disk $(5 \mathrm{~mm})$ of transformants and one disk $(5 \mathrm{~mm})$ of test pathogen were simultaneously placed on opposite sides of a PDA Petri dish and incubated at $26^{\circ} \mathrm{C}$. Three plates (replications) were used for each transformant and test pathogen based on a completely randomized design. The plates that only received the mycelial disk of pathogens are served as control ones.

The colony interaction was assayed as the percentage of the inhibition on the PDA plate after five days incubation based on the formula suggested by Sundar et al. (25). Inhibition of growth is calculated by the formula;

$(\%)=(\mathrm{X}-\mathrm{Y} \mid \mathrm{X}) \times 100$,

where $X=$ mycelial growth of pathogen in the absence of Trichoderma (control), and $\mathrm{Y}=$ mycelial growth of pathogen in the presence of transformants.

\section{Results}

Since chit42 is an essential component of chitinolytic system in T. harzianum and plays an important role in terms of mycoparasitism, we transformed T. harzianum with chit42 gene in order to reinforce the expression of this enzyme.

\subsection{Transformation of T. Harzianum by Chitinase Gene}

T. harzianum was cotransformed with the plasmid p3SR2 (containing acetamidase gene) and pLMRS3-chit42. For construction of pLMRS3-chit42, the chit42 cDNA fragment was placed between the pki1 promoter and $c b h 2$ terminator, which is confirmed by PCR and digestion pattern (Figure 1) and DNA sequencing (Data not shown).

Stable transformants were initially selected using a selective medium containing acetamide. Among 350 transformants, 80 were selected based on their ability to grow on the selective medium containing $2 \%$ colloidal chitin (2\% CCA). The selected stable amdS transformants were
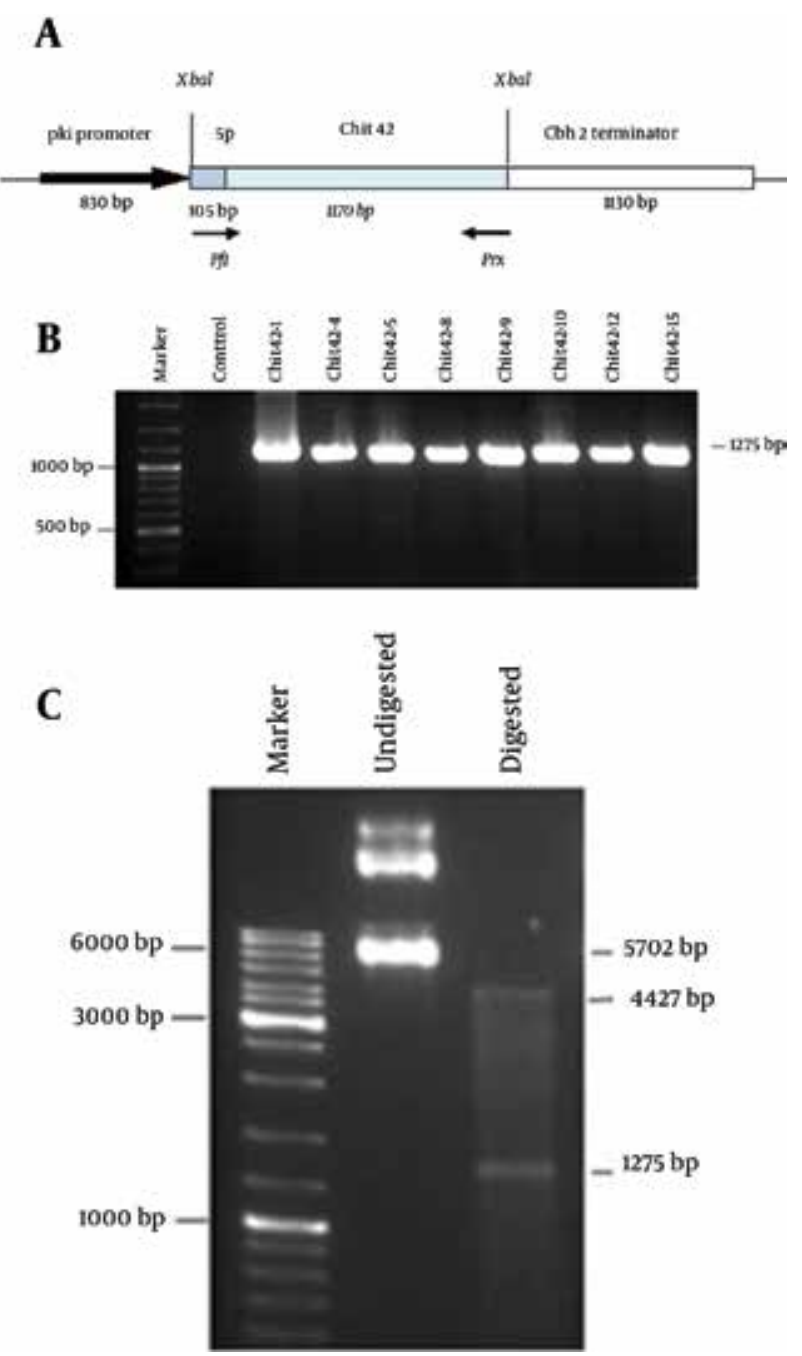

Figure 1. A) Shematic Representation of the Over Expression Cassette for Chit42 pki Pyruvate Kinase Promoter, cbh2 CellobiohydrolaseII Terminator. B) PCR amplification of the Chit42 gene using Pfi/prx specific primers (lane 3-10,eigth transformants, approximately 1275 bp), Lane 1, DNA ladder., lane 2 , negative control. C) Confirmation of pLMRS3 containing chit42 gene by digestion pattern using XbaI enzyme, Lane 2,Undigested pLMRS3-Chit42 (5702bp), Lane 3, Digested pLMRS3-Chit42 using XbaI (4427 bp \& 1275 bp fragments) 
found to have chitinase activity. Among these transformants, 16 fast growing colonies, designated Chit42-1 to Chit42-16, were selected for further study. The growth rate of the selected colonies was examined on a $0.5 \%$ CCA medium for 48 hours. Based on the mycelial growth, eight fast growing transformants (Chit42-1, -4, -5, -8, -9, -10, -12, and -15) were selected for subsequent study (Table 1 ).

\subsection{Expression Analysis by Quantitative Real-Time RT-PCR}

To quantify the expression of chit42 in the selected transformants, quantitative RT-PCR was performed using Ct values in the real-time PCR. The cDNA was prepared from the RNA of transformants and non-transformant (as negative control) grown in inducing liquid culture medium containing colloidal chitin $(2 \% \mathrm{w} / \mathrm{v})$ as the sole carbon source. Adjustment of chit42 expression levels was achieved by using $\beta$-tubulin as an internal control. Based on calculations using the $2-\Delta \Delta C T$ method differential expression folds of chit42 (ranging from 3.3 to 5.2) were detected in transformants, with the highest level of expression for Chit42-9 transformant (Table 2).

Expression analysis was performed by real-time quantitative RT-PCR using chiF/chiR primers on cDNA from $T$. harzianum transformants that have been grown on medium containing colloidal chitin. Values $(2-\Delta \Delta C T)$ correspond to comparative measurements against the chit42 transcript in the wild-type T. harzianum $(2-\Delta \Delta \mathrm{CT}=1)$. T. harzianum $\beta$-tubulin was used as an internal reference gene.

\subsection{Chitinase Activity}

The overexpression of chit42 was investigated with colloidal chitin as the carbon source. While the enzyme activity in the non-transformant was 1.97 U.ml ${ }^{-1}$, the Chit42 transformants showed improved chitinase activity from 48.72 to $126.42{\mathrm{U} . \mathrm{ml}^{-1}}^{-1}$ (Table 1 ). These results indicated that the highest chitinase activity of $126.42+0.07 \mathrm{U} / \mathrm{mL}$ in the case of Chit42-9 showed 64.17-fold increase as compared to the parent strain.

\subsection{Antifungal Activity}

To determine whether an increase in chitinase activity correlates with the antifungal activity of different transformants, dual culture tests were performed using T. harzianum and S. sclerotiorum (Figure 2). When phytopathogenic fungus and wild type or transformants of $T$. harzianum were grown in the same plates, a zone of lysis was produced in the pathogenic fungal mycelia.

Different transformants showed varied reductions with the minimum of $29 \%$ and the maximum of $89.7 \%$, in the growth rate of this pathogen (Figure 3). Among these transformants, Chit42-9 (showing the highest enzyme activity) was the best at inhibiting the growth of the pathogen tested (Figure 3 ). This transformant showed 4.98 fold more inhibitions when compared with the non-transformant. No growth was detected when pieces of the overgrown area of lysed and killed S. sclerotiorum mycelia were transferred to fresh medium (data not shown).

\begin{tabular}{lcc}
\hline Table 1. Growth Rate and Chitinase Activity of the Chit42 Transformants + SE Standard Error of Three Replicates \\
\hline Isolates & Diameter, $\mathbf{~ m m} / \mathbf{4 8 h}$ & Chitinase Activity, U.ml $^{-1}$ \\
\hline Control (nontransformed) & $17.2 \pm 0.3$ & $1.97 \pm 0.02$ \\
\hline Chit42-1 & $29.5 \pm 1.0$ & $97.02 \pm 0.56$ \\
\hline Chit42-4 & $30.0 \pm 0.5$ & $105.00 \pm 1.01$ \\
Chit42-5 & $25.0 \pm 0.3$ & $49.06 \pm 0.91$ \\
Chti42-8 & $26.5 \pm 0.4$ & $67.62 \pm 1.12$ \\
Chit42-9 & $30.5 \pm 0.9$ & $126.42 \pm 2.5$ \\
\hline Chit42-10 & $25.4 \pm 0.2$ & $49.14 \pm 0.82$ \\
Chit42-12 & $28.5 \pm 0.7$ & $90.72 \pm 2.35$ \\
\hline Chit42-15 & $25.5 \pm 0.3$ & $48.72 \pm 1.6$ \\
\hline & & $\mathbf{2}-\mathbf{\Delta} \Delta \mathbf{C T}$ \\
\hline Table 2. Analysis of Chit42 Expression of Different T. harzianum Transformants & 1.00 \\
\hline Row & Isolates & 4.1 \\
\hline $\mathbf{1}$ & Control & 4.6 \\
$\mathbf{2}$ & Chit42-1 & 3.8 \\
\hline $\mathbf{3}$ & Chit42-4 & 4.0 \\
$\mathbf{4}$ & Chit42-5 & 5.2 \\
$\mathbf{5}$ & Chti42-8 & 3.6 \\
$\mathbf{6}$ & Chit42-9 & 4.4 \\
$\mathbf{7}$ & Chit42-10 & 3.3 \\
\hline $\mathbf{9}$ & Chit42-12 & \\
\hline
\end{tabular}



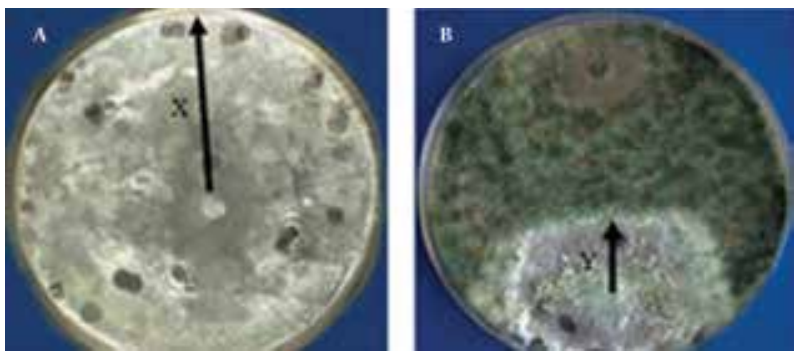

Figure 2. Dual Culture Test Using T. harzianum and S. sclerotiorum. Inhibition of growth $(\%)=(\mathrm{X}-\mathrm{Y} / \mathrm{X}) \times 100$ where, $\mathrm{X}=$ mycelial growth of $S$. sclerotio rum in the absence of Trichoderma (A), and $\mathrm{Y}=$ mycelial growth of pathogen in the presence of T. harzianum

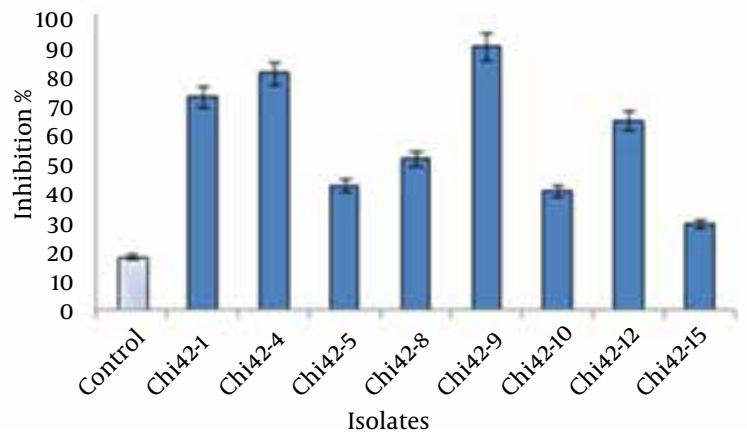

Figure 3. Analysis of the Antifungal Activity. inhibition (\%) of selected Chit42 transformants against S. sclerotiorum. Each value represents the mean ( \pm standard error) of three independent experiments. Columns are significantly different at $\mathrm{p}<0.05$.

\section{Discussion}

Canola stem rot caused by S. sclerotiorum is an important and destructive disease $(26,27)$. The disease causes high yield losses of canola in Iran (28). Due to the limitation of canola germplasm resistant to S. sclerotiorum, canola cultivars with high level of resistance are not easy to obtain by classical methods. Although application of fungicides is necessary for agricultural productivity, they have undesirable impacts on health and environment (29).

Biological control is an alternative method for managing fungal diseases (30). Biological control agents have specific advantages over synthetic fungicide, including, fewer non-target, and environmental effects, as well as lower probability of resistance development (31). Trichoderma sp. is a suitable biocontrol candidate for protection of crop yields against fungal pathogens.

Cell wall degrading enzymes such as chitinases, have been reported to have an essential role in the ability of Trichoderma to control phytopathogenic fungi (32). Chitinases produced by T. harzianum play an important role in the antagonistic effect of this fungus (13). Improvement of fungal strains by overexpression of chitinase gene in Trichoderma has contributed to intensive in creased antifungal activity against fungal pathogens (13,
33). In this research chit42 gene from T. atroviride, previously reported as a strain showing high chitinase activity (34), was overexpressed in T. harzianum under the control of a constitutive pki promoter.

Use of this promoter is an advantage for overexpression of a transgene without applying specific inducer if the transformants are to be released to control a plant disease. Overexpression of chit42 in Chit42-9 transformant (as the highest enzyme producer) increased the enzyme activity by 64 fold. A similar finding has also been reported by Limon et al. (13) using the same promoter. Carsolio et al. (9) reported a 42 fold overexpression of a chitinase gene under the control of trpC promoter from Aspergilus nidulans.

Dual culture experiment showed that the efficiency of biocontrol of transformants is higher than the wild type. This finding demonstrates the involvement of the overexpression of chit42 in biocontrol activity of T. harzianum against the S. sclerotiorum. A correlation between Trichoderma sp. biocontrol activity and cell wall degrading enzyme production has been reported in antagonistic studies $(35,36)$.

In this study, different transformants exhibited various levels of mRNA expression, chitinase activity and antagonistic effects. This fact may be due to the effect of copy numbers of the transgene, and the reflect of the transgene location on the chromosome as they have been described for other genes (37).

Our results offered positive evidence that a transgenic approach to engineer Trichoderma strains transformed with chit42 can offer much more antagonistic effect on $S$. sclerotiorum than the wild type, indicating that the overexpression of chitinase is necessary for strain improvement. Among all the transformants, Chit42-9 can be used for field assessment of antagonistic activity against Sclerotinia disease in canola.

\section{Acknowledgements}

This research was funded by National Institute of Genetic Engineering and Biotechnology (NIGEB). The authors would like to thank Prof. Dr. M. Hynes from Melbourne University of Australia for his kindly providing p3SR2 plasmid and Prof. Dr. R. L. Mach from Vienna University, Austria, who kindly donated pLMRS3 plasmid.

\section{Authors' Contribution}

Mohammad Reza Zamani and the authors conducted the study; Mostafa Motallebi: Data analysis and interpretation; and Mojegan Kowsari: contributed in all aspects of the work.

\section{Financial Disclosure}

None reported.

\section{Funding/Support}

This research was funded by National Institute of Genetic Engineering and Biotechnology (NIGEB). 
Kowsari Met al.

\section{References}

1. Woo SL, Scala F, Ruocco M, Lorito M. The Molecular Biology of the Interactions Between Trichoderma spp., Phytopathogenic Fungi, and Plants. Phytopathology. 2006;96(2):181-5.

2. Carreras VN, Sanchez AJA, Herrera EAH. Trichoderma: sensing the environment for survival and dispersal. Microbiology. 2011;158(1):3-16.

3. Vinale F, Sivasithamparam K, Ghisalberti EL, Marra R, Woo SL, Lo rito M. Trichoderma-plant-pathogen interactions. Soil Biology and Biochemistry. 2008;40(1):1-10.

4. Harman GE, Howell CR, Viterbo A, Chet I, Lorito M. Trichoderma species-opportunistic, avirulent plant symbionts. Nat Rev Microbiol. 2004;2(1):43-56.

5. Lorito M. Chitinolytic Enzymes Produced byTrichoderma harzianum: Antifungal Activity of Purified Endochitinase and Chitobiosidase. Phytopathology. 1993;83(3):302.

6. Kubicek CP, Mach RL, Peterbauer CK, Lorito M. Trichoderma. From genes to biocontrol [plant diseases]. Journal of Plant Pathology. 2001;83:11-23.

7. Lorito M. Synergistic Interaction Between Cell Wall Degrading Enzymes and Membrane Affecting Compounds. Molecular PlantMicrobe Interactions. 1996;9(3):206.

8. Garca I, Lora JM, Cruz J, Bentez T, Llobell A, Pintor-Toro J. Cloning and characterization of a chitinase (CHIT42) cDNA from the mycoparasitic fungus Trichoderma harzianum. Current Genetics. 1994;27(1):83-9.

9. Carsolio C, Benhamou N, Haran S, Cortes C, Gutierrez A, Chet I, et al. Role of the Trichoderma harzianum endochitinase gene, ech42, in mycoparasitism. Appl Environ Microbiol. 1999;65(3):929-35.

10. Limon MC, Chacon MR, Mejias R, Delgado-Jarana J, Rincon AM, Codon AC, et al. Increased antifungal and chitinase specific activities of Trichoderma harzianum CECT 2413 by addition of a cellulose binding domain. Appl Microbiol Biotechnol. 2004;64(5):67585 .

11. Brunner K, Zeilinger S, Ciliento R, Woo SL, Lorito M, Kubicek $\mathrm{CP}$, et al. Improvement of the fungal biocontrol agent Trichoderma atroviride to enhance both antagonism and induction of plant systemic disease resistance. Appl Environ Microbiol. 2005;71(7):3959-65.

12. Hartl L, Zach S, Seidl-Seiboth V. Fungal chitinases: diversity, mechanistic properties and biotechnological potential. Appl Microbiol Biotechnol. 2012;93(2):533-43.

13. Limon MC, Pintor-Toro JA, Benitez T. Increased Antifungal Activ ity of Trichoderma harzianum Transformants That Overexpress a 33-kDa Chitinase. Phytopathology. 1999;89(3):254-61.

14. Fan Y, Fang W, Guo S, Pei X, Zhang Y, Xiao Y, et al. Increased insect virulence in Beauveria bassiana strains overexpressing an engineered chitinase. Appl Environ Microbiol. 2007;73(1):295-302.

15. Boldo JT, Junges A, do Amaral KB, Staats CC, Vainstein MH, Schrank A. Endochitinase CHI2 of the biocontrol fungus Metarhizium anisopliae affects its virulence toward the cotton stainer bug Dysdercus peruvianus. Curr Genet. 2009;55(5):551-60.

16. Afshari Azad H, Important Canola Diseases. Agricultural Education Press. Tehran, Iran; 2000.

17. Lee SB, Taylor JW. PCR protocols, a guide to methods and applications. In D. G. M. Innis JAT editor. Orlando, Florida: Academic Press; 1990.

18. Sambrook J, Russell DW. Cold Spring Harbor: Laboratory Press; 2001
19. Penttilä M, Nevalainen H, Rättö M, Salminen E, Knowles J. A versatile transformation system for the cellulolytic filamentous fungus Trichoderma reesei. Gene.1987;61(2):155-64.

20. Glass NL, Donaldson GC. Development of primer sets designed for use with the PCR to amplify conserved genes from filamentous ascomycetes. Appl Environ Microbiol.1995;61(4):1323-30.

21. Livak KJ, Schmittgen TD. Analysis of relative gene expression data using real-time quantitative PCR and the 2 (-Delta Delta C(T)) Method. Methods. 2001;25(4):402-8.

22. Boller T, Mauch F. Colorimetric assay for chitinase. Meth Enzymo. 1988;161:430-5.

23. Reissig JL, Storminger JL, Leloir LF. A modified colorimetric method for the estimation of N-acetylamino sugars. J Biol Chem. 1955;217(2):959-66.

24. Ralph BL, Reynold DM. The chitinase system of a strain of Streptomyces Griseus. Biochimica et Biophysica Acta. 1958;29(3):522-34.

25. Sundar AR, Das ND, Krishnaveni D. In-vitro antagonism of Trichoderma spp. against two Fungal Pathogens of Castor. Indian J Plant Protec. 1995;23(2):152-5.

26. Hind TL, Ash GJ, Muray GM. Prevalence of Sclerotinia stem rot of canola in new south wales. Austra Jour Experi Agricul. 2003;43(2):163-168.

27. Molloy C, Cheah L, Koolaard JP. Induced resistance against Sclerotinia sclerotiorum in carrots treated with enzymatically hydrolysed chitosan. Postharvest Biology and Technology. 2004;33(1):61-5.

28. Barary H. . Sclerotinia stem rot distribution of canola in Mazandaran province. 14th Iranian Plant Protection Congress. Isfahan University of Technology, Isfahan, IR. Iran.. 2001..

29. Matarese F, Sarrocco S, Gruber S, Seidl-Seiboth V, Vannacci G. Biocontrol of Fusarium head blight: interactions between Trichoderma and mycotoxigenic Fusarium. Microbiology. 2012;158(Pt 1):98-106.

30. Reithner B, Ibarra-Laclette E, Mach RL, Herrera-Estrella A. Identification of mycoparasitism-related genes in Trichoderma atroviride. Appl Environ Microbiol. 2011;77(13):4361-70.

31. Harman GE. Myths and Dogmas of Biocontrol Changes in Perceptions Derived from Research onTrichoderma harzinumT-22. Plant Disease. 2000;84(4):377-93.

32. Papavizas GC. Trichoderma and Gliocladium: Biology, Ecology, and Potential for Biocontrol. Annual Review of Phytopathology. 1985;23(1):23-54.

33. Limon MC, Lora JM, Garcia I, de la Cruz J, Llobell A, Benitez T, et al. Primary structure and expression pattern of the 33-kDa chitinase gene from the mycoparasitic fungus Trichoderma harzianum. Curr Genet. 1995;28(5):478-83.

34. Harighi MJ, Motallebi M, Zamani MR. Purification of chitinase 42 from Trichoderma atroviride PTCC5220. Iran Jour Biol. 2006;19(2):203-14.

35. Kubicek CP, Herrera-Estrella A, Seidl-Seiboth V, Martinez DA, Druzhinina IS, Thon M, et al. Comparative genome sequence analysis underscores mycoparasitism as the ancestral life style of Trichoderma. Genome Biol. 2011;12(4):R40.

36. Ryder LS, Harris BD, Soanes DM, Kershaw MJ, Talbot NJ, Thornton CR. Saprotrophic competitiveness and biocontrol fitness of a genetically modified strain of the plant-growth-promoting fungus Trichoderma hamatum GD12. Microbiology. 2012;158(Pt1):84-97.

37. Verdoes JC, van Diepeningen AD, Punt PJ, Debets AJM, Stouthamer AH, van den Hondel AMJJ. Evaluation of molecular and genetic approaches to generate glucoamylase overproducing strains of Aspergillus niger. Journal of Biotechnology. 1994;36(2):165-75. 